\title{
Antimicrobial resistance of bacterial isolates from the clinical and hospital environment in Gaza Strip, Palestine: A review over 20-year
}

\author{
Abdelraouf A. Elmanama ${ }^{1}$, Noor E. S. Abu Tayyem¹, Isabella Sjölander²
}

\section{Abstract}

Background: Antimicrobial resistance is a serious threatening problem worldwide, associated with high morbidity and mortality. The dissemination and spread of antibiotic-resistant bacteria is influenced by several factors like inappropriate and unwise use of antibiotics as well as the un-regulated discharge of these antibiotics to the environment. A critical high rates of pathogenic bacteria isolates in Palestine are showing multiple drug resistance patterns. This fact will complicate treatment of patients suffering from bacterial infections.

Method: The study performed a review of most published articles on antibiotic resistant bacteria isolates from patients and hospital environment in Gaza strip/Palestine over the period 2002-2021 using Google scholar, Research gate, and PubMed search engines.

Results: Out of the 51 articles screened, 29 studies were met the eligibility criteria to be included in this review. The overall results of these studies have shown a high rates of multidrug-resistant gramnegative bacteria especially E. coli, Enterobacter spp., Kebsiella spp., Acinetobacter spp. and Pseudomonas aerugineosa over the study period. Also, vancomycin-resistant enterococci and methicillin-resistant Staphylococcus aureus were also commonly reported among Gram-positive bacteria.

Conclusions: The high occurrence rates of multidrug resistant bacteria isolates from patients and hospital environment in Gaza/Palestine is alarming. Therefore, there is an urgent need to develop a local plan for containment of antimicrobial resistance by implement antimicrobial stewardship.
1 Department of Medical Laboratory Sciences Faculty of Health Sciences Islamic University of Gaza, P.O. Box 108, Gaza Strip, Gaza, State of Palestine.

2 Uppsala University, Sweden.

\section{Contact information:}

Noor E. S. Abu Tayyem.

Đ nooreabutayyem@gmail.com.

\section{Keywords \\ Antimicrobial Resistance, Patients, Hospital environment, Gaza Strip, Palestine.}




\section{Introduction}

Bacterial ability to resist and overcome antimicrobial agents has been noticed since the development of these agents and their approval for use in the clinical field [1]. Antimicrobial resistance is a worldwide growing problem, leading to morbidity, mortality, and financial burden to the health-care system [2]. It is estimated that in the United States, at least 2 million patients develop serious infections due to antibiotic resistant bacteria annually [3]. It has been reported that antimicrobial resistance is one of the major public health concerns, particularly in developing countries, where the relative ease of medication availability and higher consumption rates, that have resulted in a disproportionately higher incidence of improper use of antibiotics and greater rates of resistance compared to more developed countries [4]. Additional factors contributing to the increased burden of bacterial resistance in developing countries are the weakened health infrastructure, behind scheduled presentations, the limited access to diagnostics (especially microbiology), and the reduced availability of second-line antibiotics [5]. Moreover, this alarming phenomenon may also be caused by antibiotics use in animal feed, inappropriate prescribing of antibiotics, and poor infection control strategies [6]. Wastewater from homes, industries and hospitals containing antibiotic residue are the main sources of antibiotic resistant bacteria in the environment. Additionally, the unwise use of antibiotics in clinical, agricultural, and veterinary medicine lead to the selective pressure on widely used antibiotics [3]. The hospital- acquired infections have become increasingly a major problem. It represents about 1.4 million infections worldwide each year. It is often reported that those infections caused by antibiotic-resistant bacteria originated from the hospital environment [7].

In short, bacteria exhibit resistance to antimicrobial agents through several mechanisms, including:
1. Harboring a drug efflux pump that expels (or decreases entry) antibiotics outside the cell via membrane-linked pumping proteins. It has been indicated that the multidrug efflux system is a primary determinant of aminoglycoside resistance in Pseudomonas aeruginosa $[8,9]$.

2. The production of specific enzymes that directed to nullify the effect of antibiotics. These enzymes are released through the expression of either chromosomal genes or through plasmid genes. These genes are capable of transfer through bacterial species by either horizontal gene or vertical gene transfer [10]. In this context, it is known that the production of $\beta$-lactamases is a serious threatening mechanism for $\beta$-lactam antibiotics resistance $[10,11]$. An epidemiological study by Chuma et al. (2013), reported a recent emergence of cefotaxime resistance mediated by $\beta$-lactamase in Salmonella enetrica/Serovar infantis [12].

3. Mutation of key binding elements such as ribosomal RNA or reprogramming of biosynthetic pathways [10].

4. Bacterial harboring of resistant genes within integrons or transposons, which are able to integrate and translocate to other bacterial chromosomes or plasmid, facilitate the acquiring and transferring of those genes [13, 14].

5. The chemical modification of the compound or the drug target $[15,16]$.

Gaza strip is a region of poor resources suffering from years of negligence and no clear data about the epidemiological aspects of antimicrobial resistance. Despites the contribution of weakened health service system to the antimicrobial resistance burden, it is important to look at the existing situational and attempt to analyze existing data. Thus, appropriate interventions and measures can be implemented at the community level to tackle the problem. With this background, this study aims to evaluate, investigate, and discuss the situation 
of antimicrobial resistance in the bacteria isolated from clinical samples and hospital environment in Gaza/Palestine.

\section{Materials and Methods}

This review was conducted during April 2021. Search was conducted through Google scholar, Researchgate, and PubMed (Public Medline by the National Center for Biotechnology Information) search engines. The key words used for the search included:Antimicrobial resistance, antibiotic resistance burden, antibiotic resistance, antimicrobial resistance mechanisms, resistance rate, prevalence, isolation, Gaza strip, and Palestine. The search was performed for the relevant information from Gaza strip about the antimicrobial/antibiotic resistance context since the year 2002 to 2021, which yielded 51 references. Out of these, 29 studies reported data about the antimicrobial resistance extent in Gaza Strip. Other studies were reviews, studying the antimicrobial resistance issue in different areas of interest, or considered microbes that recovered neither from clinical samples nor from hospital settings. Articles included in this review focused in the antimicrobial resistance of pathogens isolated in Gaza Strip, used Kirby-Bauer disk diffusion method, and measured antimicrobial susceptibility in adherence to Clinical and Laboratory Standards Institute (CLSI) recommendations. Excel 2010 was used to manipulate extracted data from selected studies and to draw illustrative figures and tables.

\section{Results}

\section{Overview of studies characteristics}

Fifty-one studies were screened, of these 29 were viewed and met the eligibility criteria to be included in this review. Among the 29 studies, two were retrospective in design and 27 were cross-sectional studies. Selected studies varied in their topic of in- terest, types of bacteria discussed, and source of samples investigated. However, the 29 studies can be categorized according to their topic into five sections as illustrated in Table 1.

Table 1. Sample sources of the included studies.

\begin{tabular}{|c|c|}
\hline Source of sample & No. of studies \\
\hline Urinary tract infection (uropathogens) & 7 \\
\hline $\begin{array}{l}\text { Blood Stream infections, wound, ear, pus, } \\
\text { vaginal discharge, cerebrospinal fluid, and } \\
\text { sputum (with/without urine sampling) }\end{array}$ & 6 \\
\hline Gastroenteritis & 4 \\
\hline $\begin{array}{l}\text { Burn infection, Burn units, Hospital } \\
\text { settings }\end{array}$ & 7 \\
\hline $\begin{array}{l}\text { Health care workers, their belongings, } \\
\text { surrounding environment }\end{array}$ & 5 \\
\hline Total & 29 \\
\hline
\end{tabular}

\section{Resistance pattern of bacteria recovered from urinary tract infections}

Table 2 shows the prevalence of uropathogens in the selected studies, where a Table 3 demonstrated the resistance rates of uropathogens to various tested antibiotics. Amoxicillin resistance rates ranged from $72.9 \%$ to $100 \%$ [17-21]. One study published in 2018 revealed that the resistance rate to amoxicillin/clavulanic acid was reached 99\% [20]. A study in 2006 investigated the presence of 131 $P$. aeruginosa in urine samples and found its resistance rates against amoxicillin (99\%), doxycycline (96.2\%), cephalexin (98.5\%), nalidixic acid (93.5\%), and cefaclor (97.4\%) [22]. While another study in 2004 reported the overall antibiogram of $P$. aeruginosa isolated from other clinical samples (sputum, blood, and pus) besides urine showed the highest resistance rates among amoxicillin (95.4\%), doxycycline $(64.8 \%)$, cephalexin (89.1\%), and nalidixic acid (58.8\%) [18].

In this context, a study during 2017 looked for ESBL producing Gram-negative bacteria isolated from urine and pus samples. The study stated that $28 \%$ of Escherichia coli and Klebsiella pneumonia 
Table 2. Prevalence of isolated uropathogens.

\begin{tabular}{|c|c|c|c|c|c|c|c|c|c|c|c|c|c|}
\hline \multirow{2}{*}{\multicolumn{2}{|c|}{$\begin{array}{c}\text { Year [Ref.] } \\
\text { Isolate }\end{array}$}} & \multicolumn{2}{|c|}{$2002[17]$} & \multicolumn{2}{|c|}{2004 [18] } & \multicolumn{2}{|c|}{2006 [19] } & \multicolumn{2}{|c|}{$2014[25]$} & \multicolumn{2}{|c|}{$2018[20]$} & \multicolumn{2}{|c|}{2002 [17] } \\
\hline & & No & $\%$ & No & $\%$ & No & $\%$ & No & $\%$ & No & $\%$ & No & $\%$ \\
\hline \multirow{7}{*}{$\begin{array}{l}\text { Gram } \\
\text { negative }\end{array}$} & E. coli & 70 & 57.9 & 798 & 57 & 538 & 42 & 132 & 37 & 131 & 59.8 & 1743 & 59.9 \\
\hline & Proteus spp. & 12 & 9.9 & 129 & 9.2 & 58 & 4.5 & 64 & 18 & 9 & 4.1 & 69 & 2.4 \\
\hline & Klebsiella spp. & 8 & 6.6 & 168 & 12 & 157 & 12.2 & - & - & 50 & 22.8 & 725 & 24.9 \\
\hline & P. aeruginosa & 7 & 5.8 & 81 & 5.8 & 131 & 10.2 & 57 & 16 & 16 & 7.3 & 123 & 4.2 \\
\hline & Acinetobacter spp. & 3 & 2.5 & 27 & 1.9 & \multirow{3}{*}{103} & \multirow{3}{*}{8.0} & - & - & - & - & - & - \\
\hline & Citrobacter spp. & 1 & 0.8 & 13 & 1.0 & & & - & - & - & - & - & - \\
\hline & Enterobacter spp. & 9 & 7.4 & 54 & 3.9 & & & 11 & 3 & - & - & 12 & 0.4 \\
\hline \multirow{5}{*}{$\begin{array}{l}\text { Gram } \\
\text { positive }\end{array}$} & S. aureus & 1 & 0.8 & 5 & 0.4 & 27 & 2.1 & - & - & - & - & 41 & 1.4 \\
\hline & Enterococcus spp. & 4 & 3.3 & 52 & 3.7 & 88 & 6.9 & - & - & 7 & 3.2 & 13 & 0.4 \\
\hline & S. saprophyticus/CNS & 6 & 5.0 & 63 & 4.5 & 84 & 6.5 & 47 & 13 & 6 & 2.7 & - & - \\
\hline & Streptococcus spp. & - & - & - & - & 97 & 7.6 & 47 & 13 & - & - & 98 & 3.4 \\
\hline & Positive samples & 121 & 44.8 & 1399 & 49.2 & 1637 & 34 & 38 & 10.6 & 219 & 17.2 & 2910 & 24.5 \\
\hline \multicolumn{2}{|c|}{ Total samples } & 270 & 100 & 2844 & 100 & 4778 & 100 & 358 & 100 & 1276 & 100 & 11890 & 100 \\
\hline
\end{tabular}

Table 3. The resistance pattern of the most prevalent uropathogens.

\begin{tabular}{|c|c|c|c|c|c|c|c|c|c|c|c|c|c|c|c|}
\hline Year & \multirow[t]{2}{*}{ Isolates } & \multirow[t]{2}{*}{ ntibiotic } & AMX & AMC & AN & GM & DOX & CF & CTX & CTZ & $\begin{array}{l}\text { TMP- } \\
\text { SMZ }\end{array}$ & CIP & NOR & OFX & NA \\
\hline Ref & & & $\%$ & $\%$ & $\%$ & $\%$ & $\%$ & $\%$ & $\%$ & $\%$ & $\%$ & $\%$ & $\%$ & $\%$ & $\%$ \\
\hline & & E. coli & 72.9 & 32.9 & 2.9 & 15.7 & 70 & 44.3 & 18.6 & 2.9 & 71.4 & 2.9 & 5.7 & 1.4 & 10 \\
\hline 2002 & & Proteus spp. & 83.3 & 33.3 & 8.3 & 33.3 & 83.3 & 66.7 & 41.7 & 0 & 50 & 8.3 & 8.3 & 25 & 33.3 \\
\hline & & S. saprophyticu & 66.7 & 16.7 & 0 & 66.7 & 83.3 & 83.3 & 50 & 33.3 & 83.3 & 16.7 & 33.3 & 16.7 & 100 \\
\hline & & Enterococcus & 0 & 0 & 50 & 50 & 50 & 50 & 50 & 25 & 75 & 0 & 25 & 25 & 100 \\
\hline & & E. coli & 80.1 & - & 3 & 13.4 & 59.7 & 20.8 & 15.2 & - & 58.5 & 9.1 & & & 17.6 \\
\hline & & Klebsiella spp. & 93.1 & - & 6.5 & 21.1 & 62.6 & 27.2 & 16.7 & - & 63 & 12.6 & - & - & 21.1 \\
\hline & & S. saprophyticus & 71.4 & - & - & - & 68.3 & 20.6 & 13.1 & - & 68.4 & 14.5 & - & - & - \\
\hline & & Enterococcus & 72.2 & - & - & - & 72.1 & 24.7 & 22.6 & - & 9.6 & 18.2 & - & & - \\
\hline & & E. coli & 97.9 & - & 10.6 & 11 & 90 & 50.2 & - & 13.1 & 63.9 & 19.9 & - & - & 30.6 \\
\hline & & Klebsiella spp. & 100 & - & 16.7 & 19.2 & 93 & 58.8 & - & 25.3 & 64.3 & 22.3 & - & - & 39.2 \\
\hline $\begin{array}{c}2006 \\
{[19]}\end{array}$ & & Streptococcus & 48.4 & - & 67 & 45.2 & 53.4 & 58 & - & - & 100 & 27.9 & - & - & - \\
\hline & & Enterococcus & 56.3 & - & 76.1 & 59 & 63.9 & 81.6 & - & - & 100 & 31.6 & - & - & - \\
\hline & & CNS & 92 & - & 36.9 & 25.6 & 64.1 & 58.9 & - & - & 60 & 13.2 & - & - & - \\
\hline & & E. coli & 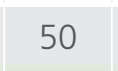 & 61.5 & 0 & - & . & - & 23.1 & 14.2 & - & - & - & 0 & 7.7 \\
\hline 4 & & Proteus & 85.7 & 50 & 0 & - & - & - & 0 & 14.3 & - & - & - & 0 & 42.9 \\
\hline & & & 75 & 25 & - & 0 & - & 0 & 0 & - & - & - & - & 0 & - \\
\hline & & Streptococcus & 0 & - & - & 100 & - & 100 & 0 & - & - & - & - & 0 & - \\
\hline & Gram r & ative & - & 99 & - & 11.2 & - & - & 81.4 & - & I9.1 & - & - & - & - \\
\hline & Gram posi & & - & - & 15.4 & 15.4 & 30.8 & - & - & - & 38.5 & - & 38.5 & - & - \\
\hline
\end{tabular}




\begin{tabular}{|c|c|c|c|c|c|c|c|c|c|c|c|c|c|c|c|}
\hline Year & \multirow[t]{2}{*}{ Isolates } & \multirow[t]{2}{*}{ Antibiotic } & AMX & AMC & AN & GM & DOX & CF & CTX & CTZ & $\begin{array}{l}\text { TMP- } \\
\text { SMZ }\end{array}$ & CIP & NOR & OFX & NA \\
\hline Ref & & & $\%$ & $\%$ & $\%$ & $\%$ & $\%$ & $\%$ & $\%$ & $\%$ & $\%$ & $\%$ & $\%$ & $\%$ & $\%$ \\
\hline \multirow{5}{*}{$\begin{array}{c}2021 \\
{[21]}\end{array}$} & \multirow{2}{*}{$\begin{array}{l}\text { Gram } \\
\text { negative }\end{array}$} & E. coli & 90 & 73 & 2 & 23 & 59 & 60 & 49 & 41 & 66 & 35 & - & 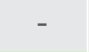 & 53 \\
\hline & & Klebsiella spp. & 95 & 68 & 4 & 29 & 66 & 73 & 62 & 49 & 69 & 38 & - & - & 50 \\
\hline & \multirow{3}{*}{$\begin{array}{l}\text { Gram } \\
\text { positive }\end{array}$} & S. aureus & 71 & 45 & 17 & 30 & 29 & 15 & 26 & 50 & 54 & 38 & - & - & 33 \\
\hline & & Streptococcus & 67 & 42 & - & 48 & 48 & 74 & 47 & - & 78 & 63 & - & - & 100 \\
\hline & & Enterococci & 100 & 50 & 63 & 54 & - & 67 & 64 & 100 & 67 & 70 & - & - & 100 \\
\hline
\end{tabular}

AMX: amoxycillin; AMC: amoxycillin-clavulanate; AN: amikacin; GM: gentamycin; DOX: doxycycline; CF: cephalexin; CTX: cefuroxime; CTZ: ceftazidime; TMP-SMZ: trimethoprim sulfamethoxazole; CIP: ciprofloxacin; NOR: norfloxacin; OFX: ofloxacin; and NA: nalidixic acid. -: The antibiotic not used in the study. *: The study showed the overall resistance rates of pathogens isolated from pus, blood, CSF besides urine.

were ESBL producers, among ESBL producers, E. coli showed the higher percentage (80.3\%), as well as $73.2 \%$ of the ESBL producers isolates were uropathogens [23].

Overall, the findings viewed in Table 2 showed that the most prevalent uropathogen was $E$. coli. Uropathogens showed high levels of multiple drug resistance, including resistance against the first, second, and third generations of cephalosporins as well as amikacin. In compared to other used antibiotics, ciprofloxacin and gentamicin resistance rates were lower [17-21]. However, a study in 2005 reported that resistance rates to ciprofloxacin were increasing among commonly UTI isolates including: Acinetobacter haemolyticus (28.6\%), S. saprophytiCus (25.0\%). P. aeruginosa (20.0\%), K. pneumonia (17.6\%), and E. coli (12.0\%). Minimal inhibitory concentration (MIC) of ciprofloxacin among the mentioned uropathogens evenly ranged from 4 to 32 $\mu \mathrm{g} / \mathrm{mL}$ with a mean of $25.0 \mu \mathrm{g} / \mathrm{mL}$ [24].

El-Astal (2004), reported the emergence of vancomycin resistance (3.2\%) in Enterococci spp. [18]. While Elmanama et al. (2018) demonstrated a steady increase in the resistance rate of Enterococci spp. to vancomycin (85.7\%) [20].

Uropathogens antimicrobial susceptibility results showed that $E$. coli were still susceptible for amikacin (100\%), ceftazidime (85.8\%), nalidixic acid (92.3\%) and ofloxacin (100\%). Also, Proteus spp. were susceptible for amikacin (100\%), ceftazidime (85.7\%), ceftriaxone (100\%), cefuroxime (100\%), and ofloxacin (100\%). However, Streptococcus spp. showed $100 \%$ resistance rate against cefazolin, cephalexin, and gentamycin [25].

A study in 2019 investigated ESBL producing uropathogens, showed that 30 isolates (35.3\%) out of total 85 were ESBL producers. Among ESBL-positive isolates, the bla $C$ CT-M gene that confer bacteria $B$ lactam-resistance was the most frequent, followed by the bla TEM $_{\text {TEM }}$ gene. ESBL producers were more resistant than non-ESBLs producers for almost all tested antibiotics [26].

\section{Resistance pattern for pathogens} recovered from Blood Stream infections (BSI), wound, pus, ear, vaginal discharge, cerebrospinal fluid (CSF), and sputum

Table 4 shows the prevalence of pathogens recovered from pus, blood, CSF, and/or Ear discharge. Whereas Table 5 shows the overall antibiotic susceptibility of bacterial isolates from the different clinical specimens $[18,22,23,27]$. According to a study in 2004 , E. coli was the most frequent causative agent of blood stream infections; its resistance rate to amoxicillin was $80.1 \%, 58.5 \%$ to cotrimoxazole, $9.1 \%$ to ciprofloxacin and $3.0 \%$ to amikacin [18]. 
Table 4. Frequency of bacterial isolates isolated from different clinical samples.

\begin{tabular}{|c|c|c|c|c|c|c|c|c|c|c|c|c|c|c|c|c|c|}
\hline \multirow{3}{*}{\multicolumn{2}{|c|}{$\begin{array}{c}\text { Year [Ref.] } \\
\text { Isolate }\end{array}$}} & \multicolumn{6}{|c|}{2004 [18] } & \multicolumn{6}{|c|}{$2006[22]^{*}$} & \multirow{2}{*}{\multicolumn{2}{|c|}{$\begin{array}{c}2015 \text { [27] } \\
\text { Ear swab or discharge }\end{array}$}} & \multirow{2}{*}{\multicolumn{2}{|c|}{$\begin{array}{c}2017 \text { [23] } \\
\text { Urine \& Pus }\end{array}$}} \\
\hline & & \multicolumn{2}{|c|}{ Pus } & \multicolumn{2}{|c|}{ Blood } & \multicolumn{2}{|c|}{ CSF } & \multicolumn{2}{|c|}{ PUS } & \multicolumn{2}{|c|}{ Blood } & \multicolumn{2}{|c|}{ Sputum } & & & & \\
\hline & & $n$ & $\%$ & $\mathrm{n}$ & $\%$ & $n$ & $\%$ & $n$ & $\%$ & $\mathrm{n}$ & $\%$ & $n$ & $\%$ & $\mathrm{n}$ & $\%$ & $\mathrm{n}$ & $\%$ \\
\hline \multirow{11}{*}{$\begin{array}{l}\text { Gram } \\
\text { negative }\end{array}$} & E. coli & 81 & 7.3 & 33 & 13.8 & 6 & 6.6 & 0 & 0 & 0 & 0 & 0 & 0 & 0 & 0 & 159 & 79.5 \\
\hline & Proteus spp. & 109 & 9.8 & 5 & 2.1 & 0 & 0 & 0 & 0 & 0 & 0 & 0 & 0 & 24 & 20 & 0 & 0 \\
\hline & K. pneumoniae & 60 & 5.4 & 13 & 5.4 & 0 & 0 & 0 & 0 & 0 & 0 & 0 & 0 & 2 & 1.7 & 41 & 20.5 \\
\hline & P. aeruginosa & 168 & 15.1 & 6 & 2.5 & 9 & 9.9 & 348 & 23.3 & 25 & 5.95 & 37 & 49.3 & 39 & 32.5 & 0 & 0 \\
\hline & Acinetobacter haemolyticus & 22 & 2.0 & 2 & 0.8 & 0 & 0 & 0 & 0 & 0 & 0 & 0 & 0 & 0 & 0 & 0 & 0 \\
\hline & Citrobacter freundi & 5 & 0.4 & 0 & 0 & 0 & 0 & 0 & 0 & 0 & 0 & 0 & 0 & 0 & 0 & 0 & 0 \\
\hline & Enterobacter cloacae & 29 & 2.6 & 4 & 1.7 & 0 & 0 & 0 & 0 & 0 & 0 & 0 & 0 & 0 & 0 & 0 & 0 \\
\hline & Neisseria meningitis & 0 & 0 & 3 & 1.2 & 18 & 19.8 & 0 & 0 & 0 & 0 & 0 & 0 & 0 & 0 & 0 & 0 \\
\hline & Serratia marcescens & 7 & 0.6 & 5 & 2.1 & 0 & 0 & 0 & 0 & 0 & 0 & 0 & 0 & 0 & 0 & 0 & 0 \\
\hline & H. Influenza & 14 & 1.2 & 10 & 4.2 & 32 & 35.2 & 0 & 0 & 0 & 0 & 0 & 0 & 0 & 0 & 0 & 0 \\
\hline & Moraxella spp. & 0 & 0 & 0 & 0 & 0 & 0 & 0 & 0 & 0 & 0 & 0 & 0 & 5 & 4.2 & 0 & 0 \\
\hline \multirow{7}{*}{$\begin{array}{l}\text { Gram } \\
\text { positive }\end{array}$} & S. aureus & 534 & 47.9 & 25 & 10.5 & 0 & 0 & 0 & 0 & 0 & 0 & 0 & 0 & 28 & 23.3 & 0 & 0 \\
\hline & S. epidermidis & 0 & 0 & 114 & 47.7 & 0 & 0 & 0 & 0 & 0 & 0 & 0 & 0 & 0 & 0 & 0 & 0 \\
\hline & S. saprophyticus/ CNS & 0 & 0 & 0 & 0 & 0 & 0 & 0 & 0 & 0 & 0 & 0 & 0 & 0 & 0 & 0 & 0 \\
\hline & Enterococcus faecalis & 69 & 6.2 & 5 & 2.1 & 0 & 0 & 0 & 0 & 0 & 0 & 0 & 0 & 0 & 0 & 0 & 0 \\
\hline & S. pneumoniae & 17 & 1.5 & 14 & 5.9 & 26 & 28.5 & 0 & 0 & 0 & 0 & 0 & 0 & 0 & 0 & 0 & 0 \\
\hline & Streptococcus spp. & 0 & 0 & 0 & 0 & 0 & 0 & 0 & 0 & 0 & 0 & 0 & 0 & 11 & 9.2 & 0 & 0 \\
\hline & Bacillus spp. & 0 & 0 & 0 & 0 & 0 & 0 & 0 & 0 & 0 & 0 & 0 & 0 & 8 & 6.7 & 0 & 0 \\
\hline \multicolumn{2}{|c|}{ Total samples } & \multicolumn{2}{|c|}{1115} & \multicolumn{2}{|c|}{239} & \multicolumn{2}{|c|}{91} & \multicolumn{2}{|c|}{1491} & \multicolumn{2}{|c|}{420} & \multicolumn{2}{|c|}{75} & \multicolumn{2}{|c|}{120} & \multicolumn{2}{|c|}{200} \\
\hline
\end{tabular}


Moreover, several studies have been revealed that $P$. aeruginosa were highly resistant to amoxicillin, cephalexin, cefaclor or cefadroxil [22, 27]. Gram negative bacteria (GNB) isolated from ear discharge showed susceptibility rates to ciprofloxacin (100\%), gentamycin (87.5-100\%) and ceftriaxone (100\%) [27]. This was in exception for $P$. aeruginosa the most common GNB isolated from pus, sputum, and ear discharge samples, that showed resistance to many antimicrobial agents by means of multiple drug resistance (MDR) $[22,27]$.

Additionally, one study focused on assessing the antimicrobial resistance of Acinetobacter spp. recovered from pus samples collected with swabs or aspirated in syringes. A total of 152 isolates of Acinetobacter spp. were identified. The isolates showed high resistance to most of the commonly used drugs. The isolates showed almost complete resistance to cephalosporins (cephalexine 98\%, cefuroxime $98.2 \%$, cefotaxime $93.2 \%$, ceftazidime $87.5 \%$, ceftriaxone $93.3 \%$, cefaclor $97.4 \%$ ), while lower rates of resistance were shown against the aminoglycosides (amikacin 68.3\%, and gentamicin $81.3 \%$ ). However, data showed that the most effective antibiotic with the least resistance rate (22.1\%) was doxycycline [28]. According to the ESBL production among GNB that reported in a study by El Aila (2017), out of 200 GNB isolates recovered from urine and pus samples,73.2\% and 26.7\% were ESBL producers, respectively [23] (Table 4).

A recent study by Elmanama et al. [29] was performed to detect the resistance pattern among Candida spp. to antifungal drugs. A total of 100 samples of vaginal swabs were collected from pregnant women. Candida spp. were isolated from $43 \%$ of the collected samples. Amphotericin B was the most effective with $0 \%$ resistance rate, followed by itraconazol and nystatin with $9.4 \%$ resistance rates for both. Resistance rate to miconazole, ketoconazole, voriconazole, and fluconazole was $11.6 \%$.

\section{Resistance pattern for pathogens recovered from patients suffering gastroenteritis}

Acute gastroenteritis is a widespread infection among children in Gaza Strip [30].

Table 5. The resistance rates of the most prevalent bacterial isolates isolated from different clinical samples.

\begin{tabular}{|c|c|c|c|c|c|c|c|c|c|c|c|c|c|c|}
\hline Year & \multirow[t]{2}{*}{ Isolates } & \multirow[t]{2}{*}{ Antibiotic } & AMX & CP & AN & GM & DOX & CTZ & CRO & CIP & $\begin{array}{l}\text { TMP- } \\
\text { SMZ }\end{array}$ & NA & TZP & MET \\
\hline Ref & & & $\%$ & $\%$ & $\%$ & $\%$ & $\%$ & $\%$ & $\%$ & $\%$ & $\%$ & $\%$ & $\%$ & $\%$ \\
\hline $\begin{array}{c}2006 \\
{[22]}\end{array}$ & $\begin{array}{l}\text { Gram } \\
\text { negative }\end{array}$ & P. aeruginosa & 99.0 & 98.5 & 34.9 & 31.4 & 96.2 & 35.8 & - & 26.1 & 94.7 & 93.5 & 61.8 & - \\
\hline \multirow{2}{*}{$\begin{array}{l}2017 \\
{[23]}\end{array}$} & \multirow{2}{*}{$\begin{array}{l}\text { E. coli \& K. } \\
\text { pneumoniae }\end{array}$} & ESBL producers & 100 & 94.6 & 34 & 38 & - & 98.2 & 96.4 & - & - & - & - & - \\
\hline & & ESBL non producers & 100 & 73 & 17.4 & 34.1 & - & 60 & 64 & - & - & - & - & - \\
\hline Year & \multirow{2}{*}{ Isolates } & \multirow{2}{*}{ Antibiotic } & AMC & CDX & CLR & GM & E & CTZ & CRO & CIP & $\mathbf{P}$ & NA & TZP\$ & MET \\
\hline Ref & & & $\%$ & $\%$ & $\%$ & $\%$ & $\%$ & $\%$ & $\%$ & $\%$ & $\%$ & $\%$ & $\%$ & $\%$ \\
\hline \multirow{4}{*}{$\begin{array}{l}2015 \\
{[27]}\end{array}$} & \multirow{2}{*}{$\begin{array}{l}\text { Gram } \\
\text { negative }\end{array}$} & $P$. aeruginosa & 79 & 97.4 & 100 & 43.6 & - & 11.3 & 19.1 & 5.2 & - & - & - & - \\
\hline & & Proteus spp. & 80 & 20 & 0 & 100 & - & 100 & 100 & 100 & - & - & - & - \\
\hline & \multirow{2}{*}{$\begin{array}{l}\text { Gram } \\
\text { positive }\end{array}$} & S. aureus & 25 & 46.4 & 46.4 & - & 35.7 & - & 0 & - & 64.3 & - & - & 25 \\
\hline & & Streptococcus spp. & 0 & 0 & 0 & - & 9.1 & - & 0 & - & 9.1 & - & - & - \\
\hline
\end{tabular}

AMX: amoxycillin; AMC: amoxycillin-clavulanate, CP: cephalexin; CDX: cefadroxil; AN: amikacin; GM: gentamycin; CLR: clarithromycin, DOX: doxycycline; E: erythromycin; CTZ: ceftazidime; CRO: ceftriaxone; CIP: ciprofloxacin; TMP-SMZ: trimethoprim sulfamethoxazole; P: penicillin; NA: nalidixic acid, TZP: Piperacillin/Tazobactam, and MET: methicillin. -: The antibiotic not used in the study data not clear. 
Table 6. Antimicrobial resistance rates among isolated enteropathogenic.

\begin{tabular}{|c|c|c|c|c|c|c|c|c|c|}
\hline \multirow{2}{*}{ Isolates } & AM & E & $\mathrm{CU}$ & GM & TE & SXT & NA & CIP & Total resistance rate \\
\hline & $\%$ & $\%$ & $\%$ & $\%$ & $\%$ & $\%$ & $\%$ & $\%$ & $\%$ \\
\hline Salmonella spp. & 0 & - & 0 & 0 & 33.3 & 0 & 33.3 & 0 & 9.5 \\
\hline Shigella spp. & 50 & - & 0 & 0 & 50 & 50 & 50 & 0 & 28.5 \\
\hline Campylobacter coliljejuni & 75 & 75 & - & - & - & - & - & 33.3 & 61.1 \\
\hline Aeromonas hydrophilia & 100 & - & 75 & 0 & 75 & 100 & 33.3 & 0 & 54.7 \\
\hline Yersinia enterocolytica & 100 & - & 0 & 0 & 100 & 100 & 100 & 0 & 57.1 \\
\hline Total resistance rate & 65 & 75 & 18.7 & 0 & 64.5 & 62.5 & 54.1 & 6.6 & 40.1 \\
\hline
\end{tabular}

AM: Amoxicillin, E: Erythromycin; CU: Cefuroxime; GM: Gentamicin; TE: Tetracycline; SXT: Trimethoprim/sulfamethoxazole; NA: Nalidixic Acid; CIP: Ciprofloxacin. -: The antibiotic not used in the study.

A study in 2012 showed that out of 132 stool samples, 12 (9.1\%) were containing enterophatogenic bacteria: Salmonella spp., Campylobacter colil jejuni, and Aeromonas hydrophilia were isolated in equal frequency $(3 / 12 ; 25 \%$ each), Shigella spp. $(2 / 12 ; 16.7 \%)$, and Yersinia enterocolytica (1/12; $8.3 \%$ ). The isolates of Campylobacter coliljejuni showed the highest antimicrobial resistance rates against both erythromycin and amoxicillin (75\%) Both Aeromonas hydrophilia and Yersinia enterocolytica showed $100 \%$ resistance to amoxicillin, tetracycline, and trimethoprim/sulfamethoxazole. Table 6 shows the resistance rates for the isolated enteric pathogens [30].

A study by Hijazi et al. (2009) estimated the prevalence of Vancomycin-Resistant Enterococcus (VRE) among hospitalized and non-hospitalized individuals. Enterococci were found in 94\% and $89 \%$ of the hospitalized and non-hospitalized individuals, respectively. VRE were isolated from $69.1 \%$ of the hospitalized patients as well as $43.3 \%$ of the nonhospitalized individuals [31].

A recent study by Qadi et al. [32] investigated the colistin resistance among Enterobacteriacae isolated from 100 clinical samples. Amikacin was the most effective antibiotic with susceptibility rate $74 \%$, followed by chloramphenicol (48\%), fosfomycin, and gentamicin (45\%). High resistance was found to trimethoprim (85\%) and tetracycline (83\%). About $41 \%$ of the isolates were considered as colistin resistant. The particular highest rates of resistance were found to be among the Proteus spp. (63.2\%), followed by Serratia spp. (57.1\%). About 39.0\% of meropenem-resistant Enterobacteriaceae was susceptible to colistin, while $45.8 \%$ of imipenem-resistant Enterobacteriaceae was susceptible to colistin. Among isolates, 89\% were MDR.

The study of Ayesh et al. [33] reported that clarithromycin resistance among $\mathrm{H}$. pylori isolates from gastric biopsy samples was $58.6 \%$ (51 samples out of total 87). Among those isolates, (4/51) $7.8 \%$ were resistant to clarithromycin, 3.9\% were positive for the $2143 A>G$ mutation, 3.9\% for 2144A>G, while none of the isolates were positive for the 2143A>C mutation.

\section{Resistance pattern for pathogens isolated from burn patients, units, HCW, and hospital settings}

One of the studies by Elmanama et al. (2013) evaluated the antibiogram of bacterial isolates from burn units. The study analyzed 118 wound samples from burn patients, 97 environmental samples, and 28 samples from health care workers (HCWs) (finger and nasal samples). Positive samples were $45.8 \%$ of the total. Pseudomonas aeruginosa was 
the most common pathogen isolated (50\%) from patients followed by Enterobacter cloacae (28.3\%). From HCWs samples, the prevalence of coagulase negative staphylococci was 29\% [34]. According to their antibiogram, Pseudomonas spp. isolates from patient samples were found to be resistant to most of the tested antibiotics including imipenem. The incidences of methicillin-resistant Staphylococci by means of oxacillin resistance were $60 \%, 77.8 \%$, and $90 \%$ in patient's samples, HCWs samples, and environmental samples, respectively [34].

Furthermore, in a study detecting ESBL producers among GNB isolated from 40 burn wound patients, $P$. aeruginosa was the predominant isolate 15 (37.5\%) followed by K. pneumoniae 10 (25\%), E. coli $9(22.5 \%)$, E. cloacae $4(10 \%)$ and A. baumannii 2 (5\%). ESBL was detected in $37.5 \%$ of the isolates. ESBL-producing isolates were $100 \%$ resistance against cefotaxime and ampicillin. A. baumannii isolates were resistant to all tested antibiotics [35]. Moreover, a previous study focused on $P$. aeruginosa ability to form biofilm and their antibiograms. Only 42 isolates were obtained from the hospital microbiology lab. Among them, 83.09\% were strong biofilm formers. The isolates were $100 \%$ resistance to ceftazidime, piperacillin (97.6\%), ciprofloxacin (28.57\%), norfloxacin (9.5\%), and both meropenem and aztreonam (2.38\%) [36]. The resistance rates of $P$. aeruginosa to piperacillin in two different studies over few years indicated the emergence of piperacillin resistant strains (Figure 1) [34, 36]. Also, high resistance rates found in A. Baumanni isolates which were isolated from neonatal intensive care units (blood samples). Forty (6.9\%) isolates from 579 samples were recovered. A. baumanni isolates were resistant to the most commonly available antibiotics. A. baumanni showed susceptibility to meropenem (92.5\%), imipenem (90\%), ciprofloxacin (75\%), gentamicin (57.5\%), and ceftriaxone (50\%) [37].

A study by Al Laham [38] investigated the antimicrobial resistance profile of bacteria recovered from

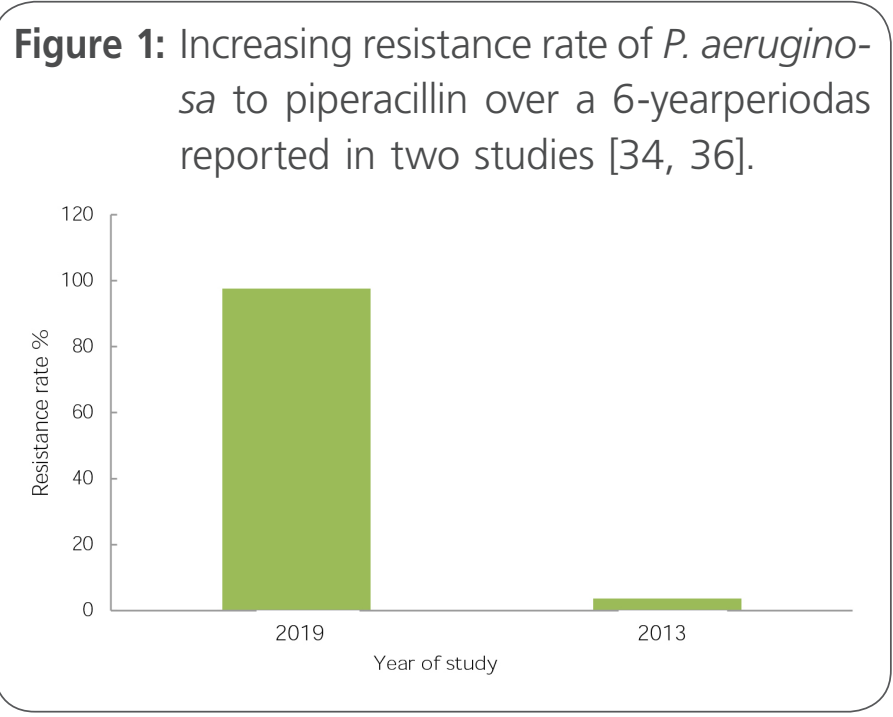

operation theaters, a total 243 swab samples were collected. About $\mathbf{2 4 . 7 \%}$ were positive for bacterial contamination. Among the isolated GNB, the overall highest resistance was $93.9 \%$ to both ampiciIlin and amoxicillin, followed by cefazolin (81.8\%). While Gram positive bacteria (that all belong to Staphylococci) showed $93.1 \%$ resistance to penicillin and $86.2 \%$ to ampicillin. Of GNB, 9.1\% were ESBL producers. Among Gram-positive bacteria, 62.1\% were methicillin resistance Staphylococcus. Methicillin resistance Staphylococcus aureus (MRSA) were $33.3 \%$, while methicillin resistance coagulase negative Staph MR-CoNS were $65.4 \%$.

The study of Rida et al. [39] focused on carbapenem resistance among GNB isolated from clinical and environmental hospital samples. The study tested 210 clinical samples, 150 environmental swabs, and 110 air samples. About 247 clinical isolates were recovered, $12.1 \%$ of them were carbapenem resistant. Resistance rate to imipenem was $8.1 \%$, while to ertapenem and meropenem was 3.5\% and $0.8 \%$, respectively. Isolates recovered from intensive care units exhibited the highest resistance rate (52.9\%). The resistance rate to carbapenem among Enterobacteriaceae was $13.2 \%$, while none of the Pseudomonas isolates were resistant to this drug. Among Enterobacteriaceae isolates, Klebsiella spp. was the mostly resistant to carbapenems (14.4\%), 
Vol. 11 No. 2:4 doi: $10.3823 / 859$ followed by $E$. coli $9.8 \%$ in addition, $23.3 \%$ were positive for carbapenemases production. All Enterobacteriaceae isolates had MDR index higher than 0.2 , while those of Pseudomonas had an average of 0.2 [39]. Another study detected the multi-resistance pattern of bacteria recovered from clinical samples in Palestine (Gaza Strip and the West Bank), Out of $248 \mathrm{GNB}$ isolated, 21 (8\%) were resistant to carbapenems and other antibiotics [40].

\section{Resistance pattern against methicillin among Staphylococcus spp. isolated from clinical and hospital setting samples.}

Several studies focused on methicillin resistance Staphylococcus. Overall studies showed MRSA prevalence ranged from $22.6 \%-82.3 \%$ [41-44].

One study focused to detect MRSA and other antibiotic resistance pattern, MRSA were recovered from HCWs nares. The highest carriage rate of MRSA was among HCWs from surgery wards. All isolates were resistant $(100 \%)$ to vancomycin and doxycycline. The multiple resistance pattern among MRSA (75\%) were higher than MSSA (44.44\%) and $61 \%$ of the isolates were MDR [41].

A second similar study showed that 62 out of $200 \mathrm{HCW}$ (31\%) carried S. aureus, of which 51 $(82.3 \%)$ were MRSA. Therefore, $25.5 \%$ of all HCWs were considered as MRSA carriers. The highest was among nurses (30.4\%) distributed in the internal medicine departments (41.3\%) and surgical wards (35\%). Penicillin has the highest resistant rates in both MRSA and MSSA (100\%) [42].

Both studies adopted the phenotypic screening for MRSA using oxacillin disk diffusion and the genotypic analysis of the mecA gene (methicillin resistance gene). Table 7 shows the resistance rate of $S$. aureus in these studies. Recent published studies in 2017 and 2020, have recorded a higher resistance rates when compared to a study reported in 2015 [41-43].

Furthermore, a recent study by Elmanama et al. [43] found that the majority of MRSA isolates (74$88.8 \%$ ) were biofilm producers. In addition, the study reported the highest resistance rate to penicillin (92.9\%), followed by cefoxitin (80.6\%) and oxacillin (67.9\%) (Table 7). About $71.4 \%$ of MRSA isolates were classified as MDR with a MAR index $(\geq 0.2)$, and $90.5 \%$ of them were biofilm producers.

A second study investigated methicillin resistance and biofilm formation among CoNS recovered from clinical samples. The study showed the highest resistance rate to aminoglycosides, $\beta$-lactams, carbapenems, cephalosporins, fosfomycin fluoroquinolones and macrolides. MR-CoNS that constituted $60 \%$ of the isolates, showed higher MDR rates than MS-CoNS. About $88.9 \%$ of isolates

Table 7. Baseline data from studies focused on methicillin resistance of Staphylococcus spp.

\begin{tabular}{|c|c|c|c|c|c|}
\hline \multicolumn{2}{|l|}{ Year [Ref.] } & 2015[41] & $2017[42]$ & $2017[44]$ & $2020[43]$ \\
\hline \multicolumn{2}{|c|}{ No. of samples } & 140 & 200 & 1121 & 196 \\
\hline \multicolumn{2}{|c|}{ Sample source } & \multicolumn{2}{|c|}{ HCWs nasal swabs } & $\begin{array}{l}\text { Pus, urine, blood, sputum, burn, } \\
\text { and surgical swabs of inpatients }\end{array}$ & $\begin{array}{l}\text { Different departments/ } \\
\text { Different sites of infection }\end{array}$ \\
\hline \multirow{6}{*}{$\begin{array}{l}\text { Prevalence } \\
\text { of bacterial } \\
\text { isolates }\end{array}$} & S. aureus & $42.1 \%$ & $31 \%$ & - & $100 \%$ \\
\hline & CONS & \multirow{4}{*}{-} & \multirow{4}{*}{-} & $100 \%$ & \multirow{4}{*}{-} \\
\hline & S. haemolyticus & & & $42 \%$ & \\
\hline & S. epidermidis & & & $32.1 \%$ & \\
\hline & S. saprophyticus & & & $16 \%$ & \\
\hline & $\begin{array}{l}\text { Methicillin } \\
\text { resistance rate }\end{array}$ & $22.6 \%$ & $25.5 \%$ & MR-CoNS: $60 \%$ & $80.6 \%$ \\
\hline
\end{tabular}


were MDR. Biofilm producers were mostly S. epidermidis (76.9\%). There was a statistically significant association between methicillin resistance and biofilm formation. The study performed the phenotypic screening for methicillin resistance through oxacillin and cefoxitin by disk diffusion method and the genotypic analysis of mecA [44]. Among swab samples from touchscreen Mobile Phones of HCWs and students. Out of the total 250 samples, $28.3 \%$ were MRSA, and $73.6 \%$ were penicillinresistant [45].

\section{Discussion}

Most recent studies are reporting that resistance rates of bacteria isolates causing human infections are significantly increasing worldwide. The precise estimates of antimicrobial resistance burden is different from one country to other, and it would be difficult to evaluate this burden from current available studies carried out in our country [46]. Also, it has been found that antimicrobial resistance has potentially high impact on patient health through increasing patient mortality and cost of treatment [46] and this issues is not possible to be obtained from these studies. Therefore, the main objective of this review is limited to present overview and discuss the magnitude of antimicrobial resistance occurrence based on bacterial isolates from clinical samples and hospital settings in Gaza/Palestine. This review article couldn't perform statistical analysis to detect the actual significant of the antimicrobial resistance for each bacterial isolates. Based on our general observation there were increasing resistance rates during the period of 20-year, and those were varied over the study period, tested specimens, laboratory methods, types of antibiotics and local regions of Gaza.

We found that all studies carried out between 2002 to 2018, have reported that most uropathogens exhibited a noticeable increase in the resistance rates to several antibiotics including ciprofloxacin, trimethoprim sulfamethoxazole, and nalidixic acid [17-21]. In particular, uropathogens were highly resistant to amoxicillin ranging from $72.9 \%$ to $100 \%$ [17-21]. One study reported that the resistance rate of uropathogens against amoxicillin/clavulanic acid was $99 \%$. Also, multidrug resistance among uropathogens has been recorded to reach $99.5 \%$ in most of GNB, while lower percentage $92.3 \%$ has been detected in Gram-positive uropathogens [20]. Studies also reported the high occurrence of multidrug of $P$. aeruginosa recovered from UTIs especially to ciprofloxacin and gentamicin [21, 24]. These results are in line with data reported by the North American UTI Collaborative Alliance (NAUTICA), about the high incidence of resistance among uropathogens to ciprofloxacin and trimethoprim sulfamethoxazole [47].

This review has also found that all published studies over the period of 20-year reported high occurrence of resistance among certain Gram-negative bacteria recovered from various clinical specimens. For example, Acinetobacter baumanni infection was associated with high mortality rate among neonatal intensive care unit infants in Gaza, since all $A$. baumannii isolates were multidrug resistance [37]. Additionally, two studies from Western Saudi Arabia and Jordan have reported that $A$. baumannii isolated from pus samples, and respiratory and environmental samples (Jordan) were mostly MDR [48, 49].

$P$. aeruginosa recovered from pus, blood, sputum, and ear discharge showed a striking MDR pattern. It resistant to amoxicillin, cephalexin, cefaclor, and cefadroxil $[22,27]$. Piperacillin-tazobactam-resistance in $P$. aeruginosa is an emerging problem. It may cause nosocomial infection. It can be isolated from clinical samples in hospitals, from the 127 intensive care units (ICUs) that participate in the Centers for Disease Control and Prevention's ICARE Project, about 6,917 $P$. aeruginosa isolates were investigated by means of susceptibility testing, and the rate of piperacillin resistance was $14.4 \%$ [50]. 
Piperacillin-tazobactam-resistant $P$. aeruginosa were found to be resistant to other antibiotics including carbapenems and aminoglycosides. Moreover, the isolation and detection of nosocomial piperacillin-tazobactam-resistant $P$. aeruginosa is challenging and may be affected by the exposure to multiple antibiotics such as: imipenem, aminoglycosides, vancomycin, and broad-spectrum [51].

Several studies showed nearly $100 \%$ resistance to B-lactam antibiotics, including carbapeneme resistance in several pathogens [18-21, 27, 35, 37, 38, 42-44]. It has been explained that the resistance against $\beta$-lactam drugs can be facilitated by $\beta$-lactamase enzyme [52]. Genotyping of ß-lactam resistant bacteria revealed that bacteria might possess genes of $\beta$-lactamase temoniera (bla $\left.\mathrm{TEM}_{\mathrm{T}}\right), \beta$-lactamase sulfhydryl variable (bla $\left.{ }_{S H V}\right), \beta$-lactamase cefotaxime hydrolyzing capability (bla ${ }_{\mathrm{CTX}-\mathrm{M}}$ ), and the $\beta$-lactamase oxacillin hydrolyzing capabilities (bla OXA $_{1}$ ) [53]. These genes may participate in co-resistance to carbapenem.

Chromosomal carbapenemase is naturally cotranscribed with other nearby $\beta$-lactamases, which could be enhanced and actively expressed by the intake of B-lactam or carbapenem antibiotics [11, 21]. Thus, B-lactam resistance could be accompanied with carbapenem resistance. It is critical to investigate the antimicrobial resistance pattern along with the prevalence of resistance genes.

Furthermore, the expressing of New Delhi metallo-beta-lactamase-1 (NDM-1) gene provides resistance to a broad range of beta-lactam antibiotics [54]. This gene confers carbapenem resistance to bacteria. Several studies confirmed the emergence of carbapenem resistant strains of bacteria [32, $34,36,39]$. One study showed that carbapenem resistant bacteria were having cabapenemase OXA51 gene group in all isolates and one isolate from Gaza was positive for NDM-2 [40]. Further studies at the molecular level are needed to clarify the mechanisms of carbapenem resistance. For instance, Daoud et al. reported that the presence of carbape- nem sensitive bacteria is positive for (NDM-1) gene that might be mutated, hence the enzyme is unable to work effectively [53].

H. pylori infections in Gaza Strip have higher resistance to clarithromycin compared to other studies from nearby populations [33]. The resistance of $H$. pylori to clarithromycin is often caused by point mutations at the domain $\mathrm{V}$ loop of the $23 \mathrm{~S}$ rRNA gene [53]. H. pylori possesses two copies of that gene. A mutation in one of the two 235 rRNA copies can be enough to cause high resistance in a dominant pattern [55]. The resistance mechanism against clarithromycin may involve the decreased ribosome binding of the macrolide so that it fails to act by interrupting protein biosynthesis [56]. Among these mutations, the three most common mutations worldwide are $2143 A>G, 2144 A>G$, and $2143 A>C$ [57]. This important finding was confirmed by the study of Ayesh et al. [33] who has recently detected clarithromycin resistance genes in H. pylori isolates in Gaza.

Few studies has reported that Extended-Spectrum Beta-Lactamase (ESBL) production as well as colistin resistance among Enterobacteriaceae isolates in Gaza becomes more prevalent in recent years [23, $32,35]$. Additionally, MRSA was highly emerged either in clinical samples or hospital environment in Gaza strip [34, 41-45].

Few data are available about the antimicrobial resistance pattern among Candida species in Gaza, thus further studies are needed on this issue.

In conclusion, this review shows the widespread of antibiotic resistance of bacteria isolated from various clinical specimens and hospital environment in Gaza Strip, Palestine over a period 20-year. In particular, there is an increase in the frequency of ESBL producing Gram-negative bacteria with overall common occurrence of MDR including Vanomycinresistance Enterococcus and MRSA. We hope that this current study will provide important information for health authorities and professionals to improve control of using antimicrobial agents. Future 
research is required to assess the actual heath and financial burden of antimicrobial resistance in our country.

\section{References}

1. Frieri M, Kumar K, Boutin A. Antibiotic resistance. JInfect Public Health 2017; 10(4):369-378. World Health Organization, Global Antimicrobial Resistance Surveillance System (GLASS) ReportEarly Implementation 2017-2018. Geneva, Switzerland, 2018.

2. Kon K, Rai M. Antibiotic Resistance: Mechanisms and New Antimicrobial Approaches. Elsevier, Academic Press 2016.

3. World Health Organization. The world health report. Geneva, 1996.

4. Frean J, Perovic O, Fensham V, McCarthy K, von Gottberg A, de Gouveia L, Poonsamy B, Dini L, Rossouw J, Keddy K, Alemu W, Yahaya A, Pierson A, Dolmazon V, Cognat S, Ndihokubwayo $J B$. External quality assessment of national public health laboratories in Africa, 2002-2009. Bull World Health Organ 2012; 90(3):191-199A.

5. Astal Z, Elmanama A, Sharif F. Antibiotic Resistance of Bacteria Associated with Community-Acquired Urinary Tract Infections in the Southern Area of the Gaza Strip. J Chemotherapy 2002; 14(3):259-264.

6. Shamsizadeh Z, Nikaeen M, Esfahani BN, Mirhoseini SH, Hatamzadeh M, Hassanzadeh A. Detection of antibiotic resistant Acinetobacter baumannii in various hospital environments: Potential sources for transmission of Acinetobacter infections. Environ. Health Prev. Med. 2017; 22(1):1-7.

7. Morita Y, Tomida J, Kawamura Y. MexXY multidrug efflux system of Pseudomonas aeruginosa. FrontMicrobiol. 2012; 3(408):1-13.

8. Lin J, NishinoK, Roberts MC, Tolmasky M, Rustam Al, Zhang L. Mechanisms of antibiotic resistance. Front Microbiol 2015; 6(34):1-3.

9. Wright GD. Bacterial resistance to antibiotics: Enzymatic degradation and modification. Adv Drug Deliv Rev 2005; 57(10): 1451-1470.

10. Elshafiee EA, Nader SM, Dorgham SM, Hamza DA. Carbapenemresistant Pseudomonas aeruginosa originating from farm animals and people in Egypt J Vet Res. 2019; 63(3):333-337.

11. Chuma T, Miyasako D, Dahshan H, Takayama T, Nakamoto Y, Shahada F, Akiba M, Okamoto K. Chronological change of resistance to beta-Lactams in Salmonella enterica serovar infantis isolated from broilers in Japan. Front. Microbiol 2013; 4:113.
12. Babakhani S, Oloomi M. Transposons: the agents of antibiotic resistance in bacteria. J Basic Microbiol 2018; 58(11): 905-917.

13. Domingues S, da Silva GJ, Nielsen KM. Integrons: Vehicles and pathways for horizontal dissemination in bacteria. Mob. Genet. Elements 2012; 2(5): 211-223.

14. BlairJ, Webber M, Baylay A, Ogbolu D, and Piddok L. Molecular mechanisms of antibiotic resistance. Reviews 2015; 13(1):42-51.

15. Wright GD. Molecular mechanisms of antibiotic resistance. Chem. Commun. 2011; 47(14):4055-4061.

16. El-Astal Z, El-Manama A, Sharif FA. Antibiotic resistance of bacteria associated with community-acquired urinary tract infections in the southern area of the Gaza Strip. J Chemother. 2002; 14(3):259-64.

17. El- Astal Z. Bacterial pathogens and their antimicrobial susceptibility in Gaza strip, Palestine. Pak J Med Sci 2004; 20(4): 365-370.

18. Elmanama A, Elaiwa NM, El-Ottol AE, Abu-Elamreen FH. Antibiotic resistance of uropathogens isolated from Al-Shifa hospital in Gaza Strip in 2002. J Chemother. 2006; 18(3):298302.

19. Elmanama A, Alreqeb A, Kalloub H, Al-Reefi M, Musallam R, Radi S, Harara Z. Bacterial Etiology of Urinary Tract Infection and their Antimicrobial Resistance Profiles. Journal of Al Azhar University-Gaza (Natural Sciences) 2018; 20(2):81-98.

20. Alkhodari S, Elmanama A. Multidrug resistance of uropathogens at governmental hospitals in the Gaza strip/Palestine. IAJAA 2021; 11(14):1-13.

21. Elmanam A. Elaiwa N, El-Ottol A, Elamreen F. Pseudomonas aeruginosa distribution in clinical samples and their antibiogram from Al-Shifa Hospital, Gaza, PNA. Annals of Alquds Medicine 2006; 2:37-45.

22. El Aila N. Prevalence and Molecular Characterization of Extended-Spectrum Beta-Lactamase Producing Escherichia Coli and Klebsiella Pneumoniae Isolated from Al Shifa Hospital, Gaza, Palestine. Al-Aqsa University Journal (Natural Sciences Series) 2017; 21:1-25.

23. El Astal Z. Increasing ciprofloxacin resistance among prevalent urinary tract bacterial isolates in Gaza Strip, Palestine. J Biomed Biotechnol. 2005; (3):238-241.

24. Elmanama A., El-Ottol A., Kandeel A., Khail G., El-banna M., Harara Y. Uropathogens and their antimicrobial susceptibility among healthy primary school children in Gaza City. 2014. Journal of Al Azhar University-Gaza (Natural Sciences). 16:37-46.

25. Tayh G, Al Laham N, Ben Yahia $H$, Ben Sallem R, Elottol AE, Ben Slama K. Extended-Spectrum $\beta$-Lactamases among Enterobacteriaceae Isolated from Urinary Tract Infections in Gaza Strip, Palestine. Biomed Res Int. 2019; 13 (2019):1-11.

26. Elmanama A, Abu Tayyem N, Nassr Allah S. The bacterial etiology of otitis media and their antibiogram among children in Gaza Strip, Palestine. Egypt J Ear, Nose, Throat Allied Sci 2015; 15(2):87-91. 
27. Elmanama A. Antimicrobial Resistance of Acinetobacter spp. Isolated from Pus Specimens from AL-Shifa Hospital, Gaza, Palestine. J. Al-Aqsa Unv 2006; 10 (S. E.).

28. Elmanama A, Al-Reefi M, Al Najjar L, Abu Eita S, Al Hag Ahmad B. Antifungal susceptibility pattern of Candida spp. isolated from vaginal discharge of pregnant women. IUG Journal of Natural Studies 2020; 28 (1):52-58.

29. Elmanam A, Abdelateef N. Antimicrobial Resistance of Enteric Pathogens Isolated from Acute Gastroenteritis Patients in Gaza strip, Palestine. IAJAA 2012; 2 (4).

30. Hijazi N, Elmanama A, Al-Hindi A. Vancomycin-resistant Enterococci in fecal samples from hospitalized patients and non-hospitalized individuals in Gaza City. J Public Health 2009; 17(1):243-249

31. Qadi M, Alhato S, Khayyat R, Elmanama A. Colistin Resistance among Enterobacteriaceae Isolated from Clinical Samples in Gaza Strip. CanJ Infect Dis \& Med Microb 2021; 2021:1-6

32. Ayesh B, Elmanama A, Abu Amra M. Clarithromycin Resistance of Helicobacter pylori Infections in Gaza Strip, Palestine. Al-Aqsa University Journal (Natural Sciences Series) 2015; 19(1):18-30.

33. Elmanama A, Laham NA, Tayh GA. Antimicrobial susceptibility of bacterial isolates from burn units in Gaza. Burns 2013; 39(8):1612-8.

34. Tayh G, Laham NA, Elmanama A, Slama K. Occurrence and antimicrobial susceptibility pattern of ESBL among Gramnegative bacteria isolated from burn units of Al Shifa hospital in Gaza, Palestine. IAJAA 2016; 5(3).

35. Elmanama A, Abu-Dan R, Eqtifan R, Shomar A, Al Rifi M. Evaluation of Biofilm Formation of Pseudomonas aeruginosa Isolated from Al-Shifa Hospital and their Susceptibility to Acetic Acid. IUG Journal of Natural Studies 2019; 27(1):19-25.

36. Al Jarousha A, El Jadba A, Al Afifi A, El Qouqa I. Nosocomial multi drug resistant Acinetobacter baumannii in the neonatal intensive care unit in Gaza City, Palestine. Int J Infect Dis 2009; 13(5):623-8.

37. Al Laham N. Distribution and Antimicrobial Resistance Pattern of Bacteria Isolated from Operation Theaters at Gaza Strip. Journal of Al Azhar University-Gaza (Natural Sciences) 2012; 14:19-34.

38. Rida RH, Al Laham N, Elmanama A. Carbapenem resistance among clinical and environmental Gram-negative isolates recovered from hospitals in Gaza strip, Palestine. Germs 2018; 8(3):147-154.

39. Sjolander I, Hansen F, Elmanama A, Khayyat R, Abu-Zant A, Hussein A, Abu Taha A, Hammerum A, Ciofu O. Detection of multidrug-resistant bacteria in the occupied Palestinian territory: a cross-sectional study. The lancet 2017; 390(1):S12.
40. AL Laham N. Detection and Antibiotic Resistance Pattern of Staphylococcus aureus and MRSA Isolated from Healthcare Workers Nares at Gaza Hospitals, Palestine. IAJAA 2015; 5(4):2.

41. El Aila NA, Al Laham NA, Ayesh BM. Nasal carriage of methicillin resistant Staphylococcus aureus among health care workers at Al Shifa hospital in Gaza Strip. BMC Infect Dis. 2017; 17(1):28.

42. Elmanama A, AL-Aydi I, AL-Reefi M. Biofilm Formation and Methicillin Resistance of Staphylococcus aureus Isolated from Clinical Samples. IAJAA 2020; 10(1).

43. AL Laham N, Abou Elkhair E, Bashir A, Abdelateef N. Resistance profiles and biofilm formation of coagulase negative staphylococci isolated from clinical specimens in a tertiary care hospital in Palestine. IAJAA 2017; 7(3).

44. Elmanama A, Hassona I, Marouf A, Alshaer G, Abu Ghanima E. Microbial Load of Touch Screen Mobile Phones Used by University Students and Healthcare Staff. Journal of the Arab American University 2015; 1 (1):1-21.

45. Naylor NR, Atun R, Zhu N, Kulasabanathan K, Silva S, Chatterjee A, Knight GM, Robotham JV. Estimating the burden of antimicrobial resistance: a systematic literature review. Antimicrob Resist Infect Control 2018; 25(7):58.

46. Zhanel GG, Hisanaga TL, Laing NM, DeCorby MR, Nichol KA, Palatnick LP, Johnson J, Noreddin A, Harding GK, Nicolle LE, Hoban DJ. Antibiotic resistance in outpatient urinary isolates:final results from the North American Urinary Tract Infection Collaborative Alliance (NAUTICA). Int J Antimicrob Agents 2005; 26(5):380-8.

47. Shah MW, Yasir M, Farman M, Jiman-Fatani AA, Almasaudi SB, Alawi M, El-Hossary D, Azhar El. Antimicrobial Susceptibility and Molecular Characterization of Clinical Strains of Acinetobacter baumannii in Western Saudi Arabia. Microb Drug Resist 2019; 25(9):1297-1305.

48. Nathir Obeidat, Fatin Jawdat, Amal G. Al-Bakr, Asem A. Shehabi. Major biological characteristics of Acinetobacter baumannii isolates form hospital environmental and patients' respiratory tract sources. A J Infect Cont 2014; 42:401-4.

49. Centers for Disease Control and Prevention. 1996. National Nosocomial Infections Surveillance (NNIS) Report, October 1986-April 1996. AmJ Infect. Control 24:380-388.

50. Harris AD, Perencevich E, Roghmann MC, Morris G, Kaye KS, Johnson JA. Risk factors for piperacillin-tazobactam-resistant Pseudomonas aeruginosa among hospitalized patients. Antimicrob Agents Chemother. 2002; 46(3):854-8.

51. Manoharan A, Chatterjee S, Mathai D, SARI Study group. Detection and characterization of metallo beta lactamases producing P. aeruginosa. Indian J Med Microbiol 2010; 28(3):241-4. 
52. Daoud Z, Farah J, Sokhn ES, El Kfoury K, Dahdouh E, Masri K, Afif C, Abdel-Massih RM, Matar GM. Multidrug-Resistant Enterobacteriaceae in Lebanese Hospital Wastewater: Implication in the One Health Concept. Microb Drug Resist 2018; 24:166-174.

53. Taylor DE, Ge Z, Purych D, Lo T, Hiratsuka K. Cloning and sequence analysis of two copies of a 235 rRNA gene from Helicobacter pylori and association of clarithromycin resistance with 235 rRNA mutations, Antimicrob Agents Chemother 1997; 41(12):2621-8.

54. Hultén K, Gibreel A, Sköld O, Engstrand L. Macrolide resistance in Helicobacter pylori: mechanism and stability in strains from clarithromycin-treated patients, Antimicrob Agents Chemother 1997; 41(11):2550-3.

55. Owen R. Molecular testing for antibiotic resistance in Helicobacter pylori, Gut 2002; 50(3):285-9.

56. Xiong LJ, Tong Y, Wang Z, Mao M. Detection of clarithromycinresistant Helicobacter pylori by stool PCR in children: a comprehensive review of literature, Helicobacter 2013; 18(2):89101.

\section{Publish in The International}

Arabic Journal of Antimicrobial Agents

The Journal is an open access peer-reviewed journal that publishes scientific papers about all aspects of antimicrobials. The journal will publish original research articles, reviews, brief reports and case reports dealing with basic and clinical antibacterial agents, antiviral, antiprotozoals, antituberculuous, antifungal and antihelminthes agents. All manuscripts must be prepared in English, and are subject to a rigorous and fair peer-review process. Accepted papers will immediately appear online. The journal aims to advance the knowledge, attitude and the research of chemotherapy in the Arabic world in cooperation with international, national scientific and public societies as well as research centers with similar aims and objectives. 